\title{
Rapid Biosynthesis of Silver Nanoparticles Using Cymbopogan Citratus (Lemongrass) and its Antimicrobial Activity
}

\author{
Shalaka A. Masurkar*, Pratik R. Chaudhari, Vrishali B. Shidore, Suresh P. Kamble
}

(Received 20 July 2011; accepted 22 September 2011; published online 27 September 2011.)

\begin{abstract}
The present study deals with the rapid green synthesis of silver nanoparticles using fresh leaves of Cymbopogan Citratus (Lemongrass). Silver nanoparticles were formed within 8 10 minutes by microwave irradiation using aqueous solution of $\mathrm{AgNO}_{3}(1 \mathrm{mM})$ with fresh leaves extract of Cymbopogan Citratus. The synthesized silver nanoparticles were characterized by using UV-visible spectrophotometer analysis, nanoparticle tracking analyzer, transmission electron microscope and energy dispersive X-ray spectra. The antibacterial activity of these nanoparticles was studied against multiple drug resistant hospital isolates of E.coli, S.aureus, P.mirabilis and hospital isolates of S. typhi, K.pnuemoniae. Also, the antifungal activity of these nanoparticles was studied against C.albicans (hospital isolate) and A.niger (NCIM 616). The synergistic effect of silver nanoparticles along with antibiotics was also studied against multiple drug resistant hospital isolates and found to be effective. The extracellular synthesis of Silver nanoparticles using leaves of Cymbopogan Citratus appears to be rapid and eco-friendly.
\end{abstract}

Keywords: Green synthesis; Cymbopogan Citratus; Nanoparticle tracking analyzer; Transmission electron microscope; Energy dispersive X-ray spectra

Citation: Shalaka A. Masurkar, Pratik R. Chaudhari, Vrishali B. Shidore and Suresh P. Kamble, "Rapid Biosynthesis of Silver Nanoparticles Using Cymbopogan Citratus (Lemongrass) and its Antimicrobial Activity", Nano-Micro Lett. 3 (3), 189-194 (2011). http://dx.doi.org/10.3786/nml.v3i3.p189-194

\section{Introduction}

Nanoparticles are being considered to be the fundamental building blocks of nanotechnology. Nanotechnology is interdisciplinary which includes physics, chemistry, biology, material science and medicine. An important aspect of nanotechnology deals with the development of experimental processes for the synthesis of nanoparticles of different sizes, shape and controlled dispersity. Nanoscale materials and structures are usually ranging from $1 \sim 100 \mathrm{~nm}$ and is emerging area of nanoscience and nanotechnology. Synthesis of noble nanoparticles for the applications such as catalysis, electronics, environmental and biotechnology is an area of constant interest $[1,2]$.
Generally metal nanoparticles are synthesized and stabilized by using physical and chemical methods: the chemical methods, such as chemical reduction $[3,4]$, electrochemical techniques [5], and now a day via green chemistry route [6]. The biological methods are preferred than chemical methods because of the use of toxic chemicals on the surface of nanoparticles and non-polar solvents in the synthesis procedure limits their applications in clinical fields [7]. Therefore, development of clean, biocompatible, non-toxic and eco-friendly methods for nanoparticles synthesis has great importance. These biological methods are regarded as safe, costeffective, sustainable and environment friendly as well as it do not require any special culture preparation and isolation techniques [8]. 
Till now various plants have been used for synthesis of silver nanoparticles like Pongamia pinnata $(L)$ pierre [9], Allium cepa [10], Gliricidia sepium [11], Azadirachta indica [12], Carica papaya [13], Phyllanthus amarus [14]. Shankar et al. [15] used lemongrass and geranium plant extracts to induce the formation of gold nanoparticles.

In present study, the fresh leaves extract of Cymbopogan citratus (Lemongrass) obtained by boiling the leaves in distilled water and it was used to synthesize silver nanoparticles from silver nitrate. The synthesized silver nanoparticles were characterized by using UV-visible spectrophotometer, nanoparticles tracking analyzer (NTA) and transmission electron microscopy (TEM) and energy dispersive X-ray spectra (EDX). After characterization silver nanoparticles were used for antibacterial and antifungal testing.

\section{Materials and Methods}

\section{Preparation of leaf extract}

Fresh leaves of Cymbopogan citratus (Lemongrass) were collected from local farm of Loni village, MS, India. The leaves were washed thoroughly with distilled water. About $50 \mathrm{gm}$ of leaves were cut into small pieces. Finely cut leaves were dipped into a beaker containing $200 \mathrm{ml}$ distilled water. After that the mixture was boiled for 10 12 minutes. The extract was filtered using Whatmann filter paper and filtrate was collected.

Synthesis of silver nanoparticles using extract of Cymbopogan citratus (Lemongrass) leaves

The extract of Cymbopogan citratus (Lemongrass) leaves was mixed with aqueous solution of $1 \mathrm{mM}$ Silver nitrate $(99.99 \%)$ in 1:4 ratio in conical flask under aseptic conditions. The $\mathrm{pH}$ was adjusted to 8.0. The conical flasks were then incubated at $37^{\circ} \mathrm{C}$ for 24 hours. A change in the color of the solution was observed.

\section{Microwave irradiation mediated synthesis of sil- ver nanoparticles}

The extract of Cymbopogan citratus (Lemongrass) leaves was mixed with aqueous solution of $1 \mathrm{mM}$ Silver nitrate in 1:4 ratio in conical flask under aseptic conditions. The $\mathrm{pH}$ was adjusted to 8.0. The solution was subjected to microwave irradiation (90 watts) till color change was observed.

\section{UV-visible spectrophotometer analysis}

After observing color change, the sample was subjected to mild sonication for 10 minutes. The bioreduction of silver ions in aqueous solution was monitored by UV-Vis spectra of the solution between $300 \sim 600 \mathrm{~nm}$ using Thermo-Biomate $3 \mathrm{UV}$-visible spectrophotometer.
Distilled water was taken to adjust the baseline.

\section{Nanoparticle tracking analyzer (NTA) measure- ments}

NTA analysis was carried out by using NanosightLM20 instrument. $0.3 \mathrm{ml}$ samples were introduced to the viewing unit using a disposable syringe and enhanced by a near perfect black background; particles appear individually as point-scatterers moving under brownian motion.

Transmission electron microscopy (TEM) and energy dispersive X-ray spetra (EDX) analysis

Transmission electron microscopy (TEM) analysis of the sample was done using PHILIPS-CM 200 instrument operated at an accelerating voltage of $200 \mathrm{kV}$ with resolution of $0.23 \mathrm{~nm}$. A drop of solution was placed on carbon coated copper grid and later exposed to infrared light (45 minutes) for solvent evaporation. The EDX analysis was carried out using JEOL JSM 7600F.

\section{Antibacterial Studies}

The antibacterial activity of synthesized silver nanoparticles was studied against multiple drug resistant hospital isolates of E.coli, S.aureus, P.mirabilis and hospital isolates of S.typhi, K.pnuemoniae (obtained from Department of Microbiology, Pravara Institute of Medical Sciences, Loni, MS, India).

\section{Antifungal Studies}

The antifungal activity was checked against C.albicans (hospital isolate) and A.niger (NCIM 616).

\section{Well diffusion method}

The well diffusion test was performed using Muller Hinton Agar no. 2. (Casein acid hydrolysate 17.50 $\mathrm{gm} / \mathrm{L}$, Beef heart infusion $2 \mathrm{gm} / \mathrm{L}$, Starch soluble 1.5 $\mathrm{gm} / \mathrm{L}$, Agar $17 \mathrm{gm} / \mathrm{L}, \mathrm{pH} 7.3 \pm 0.2$ ). The inoculum was prepared in sterile Nutrient Broth (Peptone $10 \mathrm{gm} / \mathrm{L}$, Beef extract $10 \mathrm{gm} / \mathrm{L}$, Sodium chloride $5 \mathrm{gm} / \mathrm{L}, \mathrm{pH}$ 7.3) and the tube was incubated at $37^{\circ} \mathrm{C}$ until the turbidity was achieved up to the 0.5 McFarland standard (usually overnight) [16]. For A.niger inoculum preparation, spores were collected from 7 days old culture of A.niger with the help of sterile nicrome loop dipped in normal saline $(0.85 \% \mathrm{w} / \mathrm{v})$ containing Tween-20 $(0.1 \%$ $\mathrm{v} / \mathrm{v}$, Sigma Chemicals). Spore count was adjusted in the range of $1 \times 10^{6}$ to $5 \times 10^{6}$ spores $/ \mathrm{ml}$ by haemocytometer count [17].

The Mueller-Hinton agar no. 2 plate was inoculated with $2 \mathrm{ml}$ of inoculum by streaking the swab over plate. Then, agar was punched with help of sterile borer to create $6 \mathrm{~mm}$ well. $30 \mu \mathrm{l}$ of different concentrations of 
antibiotics (Table 1) and nanoparticles solution were added in respective wells. Sterile distilled water and silver nitrate $(1 \mathrm{mM})$ were used as a control. To study synergistic effect of silver nanoparticles and antibiotics, the mixture of $15 \mu \mathrm{l}$ of respective concentration of silver nanoparticles and $15 \mu \mathrm{l}$ of antibiotics solution was added into respective wells (Table 2). Plates were incubated at $37^{\circ} \mathrm{C}$ for $18 \mathrm{hr}$ in upward position. Zone of inhibition was measured after incubation with HiMedia scale. The whole experiment was performed in duplicates.

\section{Results and Discussion}

\section{Synthesis of silver nanoparticles using leaf ex- tract of Cymbopogan citratus}

No color change was observed upon mixing the leaves extract of Cymbopogan citratus with aqueous solution of $1 \mathrm{mM}$ silver nitrate in 1:4 ratio ( $\mathrm{pH} 8.0$ ), which was incubated at $37^{\circ} \mathrm{C}$ over for 24 hours. Although, the color change was observed within 8 10 minutes when the mixture of the extract of Cymbopogan citratus leaves and aqueous solution of $1 \mathrm{mM}$ silver nitrate was added in 1:4 ratio ( $\mathrm{pH}$ 8.0) upon microwave irradiation (Fig. 1). It was reported that thermal factors have been demonstrated to affect the size and uniformity of nanoparticles [11] and also increased $\mathrm{pH}$ and temperature fastens the rate of synthesis of silver nanoparticles [12]. Debris, if any, was removed by centrifugation at $1500 \mathrm{rpm}$ for 5 minutes. After centrifugation, the supernatant was collected and was re-centrifuged at 13,000 rpm for 30 45 minutes. The silver nanoparticles pellet was suspended in sterile distilled water and it was used for further applications.

Table 1 List of microorganisms used with respective Antibiotics/Antifungals.

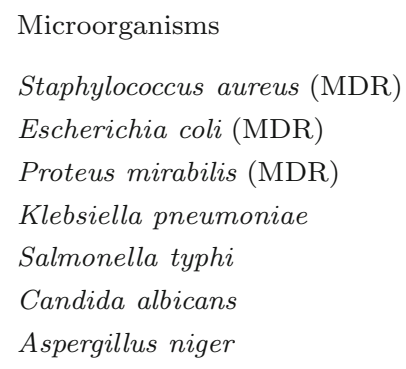

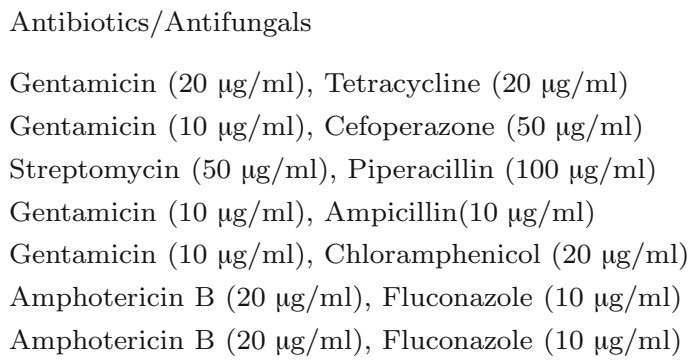

Table 2 Abbreviations.

I
II
III
IV
I+Antibiotics
II+Antibiotics
III+Antibiotics
IV+Antibiotics
$10 \%$ of concentrated Silver Nanoparticles
$25 \%$ of concentrated Silver Nanoparticles
$50 \%$ of concentrated Silver Nanoparticles
$75 \%$ of concentrated Silver Nanoparticles
$15 \mu \mathrm{l}, 10 \%$ of concentrated respective Silver Nanoparticles $+15 \mu \mathrm{l}$ of respective concentration of antibiotic
$15 \mu \mathrm{l}, 25 \%$ of concentrated respective Silver Nanoparticles $+15 \mu \mathrm{l}$ of respective concentration of antibiotic
$15 \mu \mathrm{l}, 50 \%$ of concentrated respective Silver Nanoparticles $+15 \mu \mathrm{l}$ of respective concentration of antibiotic
$15 \mu \mathrm{l}, 10 \%$ of concentrated respective Silver Nanoparticles $+15 \mu \mathrm{l}$ of respective concentration of antibiotic
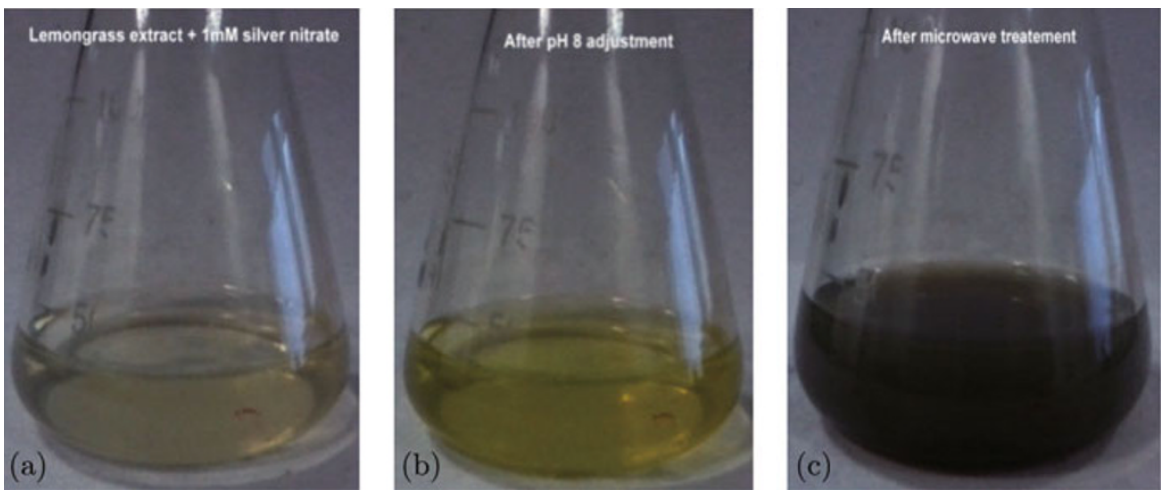

Fig. 1 (a) Initial reaction mixture containing extract of Cymbopogan citratus leaves and 1 mM silver nitrate in 1:4 ratio; (b) Color change of reaction mixture after adjusting $\mathrm{pH} 8.0$; (c) Color change of reaction mixture after microwave irradiation. 


\section{UV-visible spectrophotometric analysis}

The synthesis of silver nanoparticles by reduction of aqueous metal ions during exposure of Cymbopogan citratus leaves extract can be easily monitored by using UV-visible spectrophotometry. Figure 2 illustrates the absorbance spectra of reaction mixture containing aqueous solution of $1 \mathrm{mM}$ silver nitrate and extract of Cymbopogan citratus leaves after microwave irradiation. Reaction mixture showed an absorbance peak at around $430 \mathrm{~nm}$, which is characteristic of silver nanoparticles, due to its surface plasmon resonance absorption band [18].

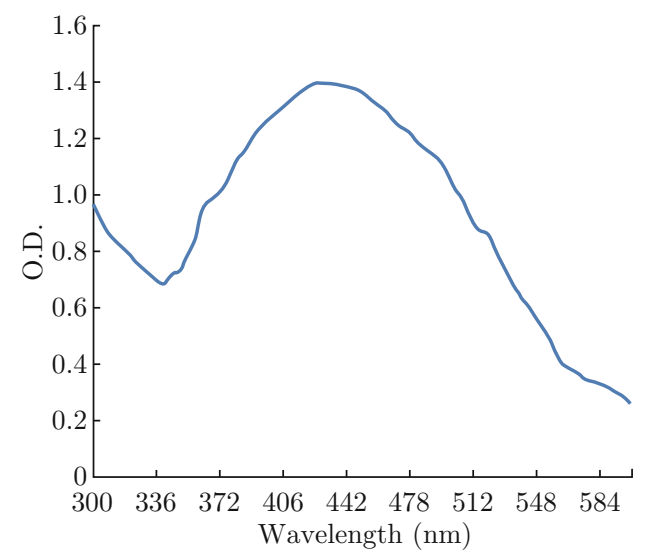

Fig. 2 UV-visible spectrophotometer analysis of silver nanoparticles synthesized using extract of fresh Cymbopogan citratus (Lemongrass) leaves.

\section{NTA measurements}

NTA measurements revealed that the mean size of synthesized silver nanoparticles was found to be $32 \mathrm{~nm}$ (Fig. 3) with concentration of $6.3 \times 10^{10}$ particles $/ \mathrm{ml}$. The brownian motion of silver nanoparticles was recorded as video clip. No aggregations or debris were detected on NTA measurements.

\section{TEM and EDX analysis}

TEM analysis revealed that the silver nanoparticles are prominently spherical (Fig. 4). The TEM image at high resolution also revealed that silver nanoparticles are not in physical contact but are separated by uniform distance. The capping of silver nanoparticles was also observed under TEM micrograph. This capping might be because of presence of bio-organic compounds present in extract [13]. The EDX analysis revealed that the silver is present in the solution (Fig. 5). The silver content in the particles was found to be $69.81 \%$.

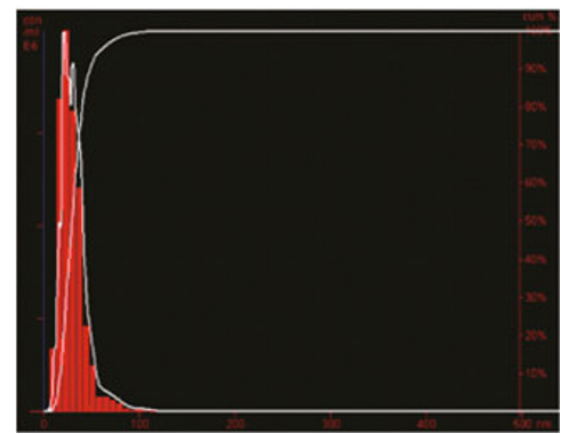

Fig. 3 Frequency size distribution graph of silver nanoparticles synthesized using extract of fresh Cymbopogan citratus (Lemongrass) leaves; $\mathrm{X}$ axis: particles size (nm), $\mathrm{Y}$ axis: concentration $/ \mathrm{ml} \times 10^{6}$.

\section{Antimicrobial studies}

The antibacterial activity of silver nanoparticles was checked against multiple drug resistant hospital isolates of E.coli, S.aureus, P.mirabilis and hospital isolates of S.typhi, K.pnuemoniae. The antifungal activity was checked against C.albicans (hospital isolate) and A.niger (NCIM 616). Two antibiotics were served as a control for each microorganism (Table 1, 3). Silver nanoparticles showed clear zone of inhibition against all tested microorganisms. Zone of inhibition was found to be in the range of $13 \sim 16 \mathrm{~mm}$ for various tested bacteria and 15 18 mm for tested fungi (Fig. 6, Fig. 7). The synergistic effect of silver nanoparticles along with antibiotics was also checked on various multiple drug resistance pathogenic bacteria. The synergistic effect was found to be more prominent than effect of antibiotics alone.
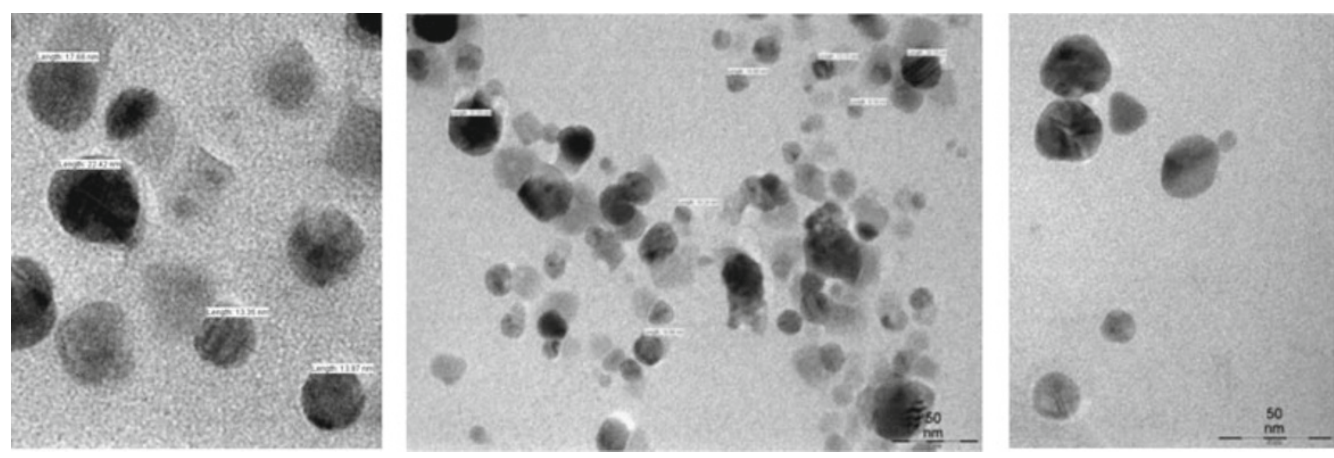

Fig. 4 TEM micrograph of silver nanoparticles synthesized using extract of Lemongrass fresh leaves. 
Table 3 Zone of inhibition of Antibiotics/Antifungals and control used with respective microorganisms.

Microorganism
E.coli
S.aureus
P.mirabilis
K.pnuemoniae
S.typhi
C.albicans
A.niger

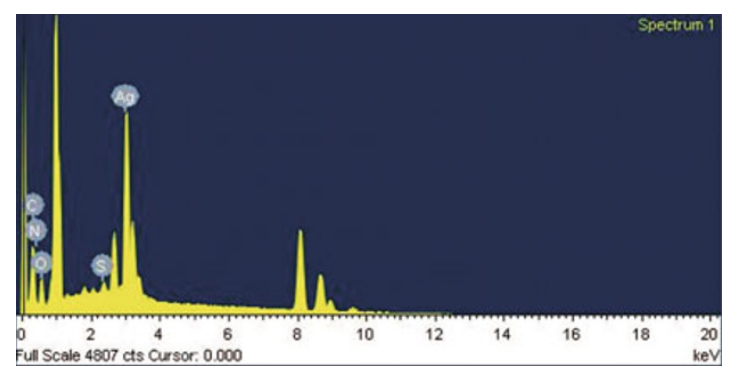

Fig. 5 EDX spectra of silver nanoparticles solution.

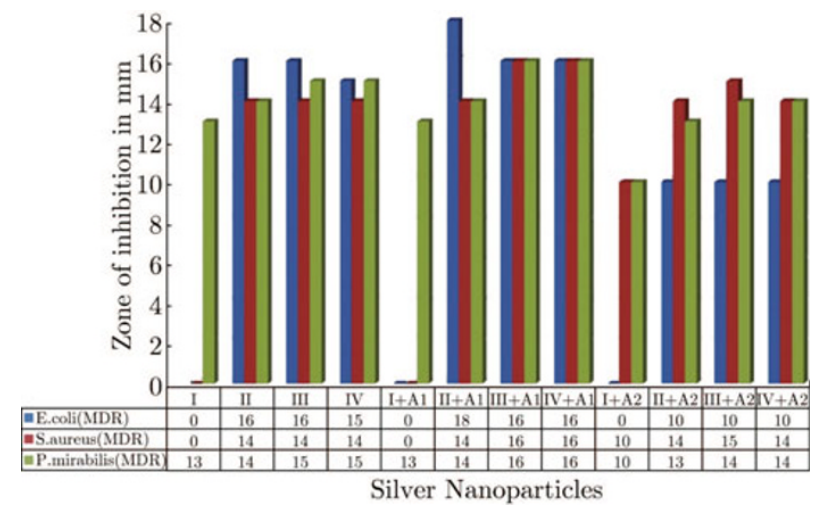

Fig. 6 Effect of silver nanoparticles synthesized using Cymbopogan citratus (Lemongrass) leaves extract on various microorganisms.

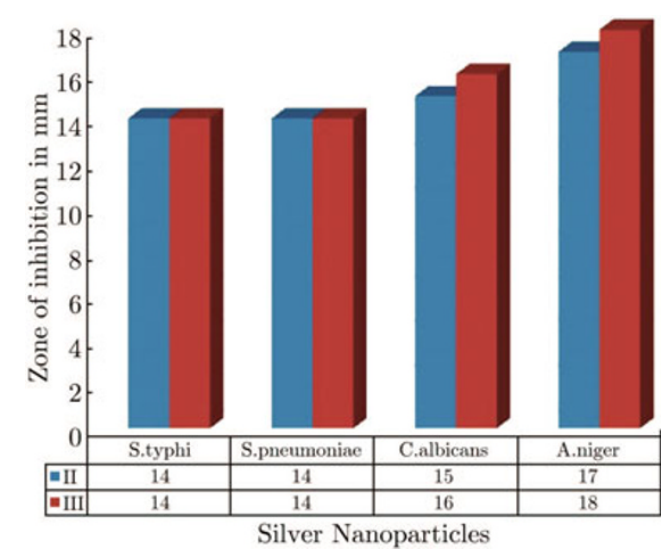

Fig. 7 Effect of silver nanoparticles synthesized using extract of Cymbopogan citratus (Lemongrass) leaves on bacteria and fungi.
Zone of inhibition of
Zone of inhibition for
distilled water in $\mathrm{mm}$
$1 \mathrm{mM}$ silver nitrate in $\mathrm{mm}$

Gentamycin- 0

Piperacillin- 0

Fluconazole- 20

Fluconazole- 0

10
10
10
10
10
0
0

\section{Conclusion}

The silver nanoparticles were green synthesized using leaf extract of Cymbopogan citratus. The method represents an example of clean, nontoxic and ecofriendly method for obtaining silver nanoparticles. Further, the above nanoparticles revealed to possess antibacterial activity against multiple drug resistant hospital isolates of E.coli, S.aureus, P.mirabilis and hospital isolates of S.typhi, K.pnuemoniae, as well as antifungal activity against C.albicans (hospital isolate) and A.niger (NCIM 616). Synergistic effect of silver nanoparticles and antibiotics was found to be effective against multiple drug resistant bacteria. The present study emphasizes the use of plant materials for the synthesis of silver nanoparticles with antibacterial and antifungal effect.

\section{Acknowledgements}

We are thankful to Dr. Razia Kutty and Mr. Rajesh Raut for their priceless help. We sincerely acknowledge the facilities provided by Dept. of Botany, Institute of Science, Mumbai and SAIF, IIT Powai, Mumbai. We are also thankful to Pravara Institute of Medical Sciences, Loni, Ahmednagar (MS), India for the financial support.

\section{References}

[1] I. Hussain, M. Brust, A. J. Papworth and A. I. Cooper, Langmuir 19, 4833 (2003). http://dx.doi.org/10. 1021/la020710d

[2] V. K. Sharma, A. Y. Ria and L. Yekaterina, J. Colloid Interf. Sci. 145, 83 (2009). http://dx.doi.org/ $10.1016 /$ j.cis. 2008.09.002

[3] K. Balantrapu and V. Goia Dan, J. Mater. Res. 24, 2828 (2009). http://dx.doi.org/10.1557/jmr. 2009. 0336

[4] R. M. Tripathi, A. Saxena, N. Gupta, H. Kapoor and R. P. Singh, Digest J. Nanomat. Biostruct. 5, 323 (2010). 
[5] L. Rodriguez-Sanchez, M. C. Blacno and M. A. LopezQuintela, J. Phys. Chem. 104, 9683 (2000). http:// dx.doi.org/10.1021/jp001761r

[6] N. A. Begum, S. Mondal, S. Basu, R. A. Laskar and D. Mand, Colloids Surf. B 71, 113 (2009). http://dx. doi.org/10.1016/j.colsurfb. 2009.01.012

[7] B. N. Kannan and N. Sakthivel, Adv. Colloid Interf. Sci. 156, 1 (2010). http://dx.doi.org/10.1016/j. cis. 2010.02.001

[8] J. L. Gardea-Torresdey, J. G. Parsons, E. Gomez, J. Peralta-Videa, H. E. Troiani, P. Santiago and M. J. Yacaman, Nano Lett. 2, 397 (2002). http://dx.doi. org/10.1021/nl015673+

[9] R. W. Raut, N. S. Kolekar, J. R. Lakkakula, V. D. Mendhulkar and S. B. Kashid, Nano-Micro Lett. 2, 106 (2010). http://dx.doi.org/10.5101/nml.v2i2. p106-113

[10] A. Sexena, R. M. Tripathi and R. P. Singh, Digest J. Nanomat. Biostruct. 5, 427 (2010).

[11] R. Raut, S. L. Jaya, D. K. Niranjan, B. M. Vijay and S. Kashid, Curr. Nanosci. 5, 117 (2009). http://dx. doi.org/10.2174/157341309787314674
[12] S. S. Shankar, A. Rai, A. Ahmad and M. Sastry, J. Colloid Interf. Sci. 275, 496 (2004). http://dx.doi. org/10.1016/j.jcis.2004.03.003

[13] N. Mude, A. Ingle, A. Gade and M. Rai, J. Plant Biochem. Biotechnol. 18, 83 (2009).

[14] J. Kasthuri, K. Kathiravan and N. Rajendiran, J. Nanopart. Res. 11, 1075 (2009). http://dx.doi.org/ 10.1007/s11051-008-9494-9

[15] S. S. Shankar, A. Rai, B. Ankamwar, A. Singh, A. Ahmad and M. Sastry, Nature Mater. 3, 482 (2004). http://dx.doi.org/10.1038/nmat1152

[16] NCCLS (National Committee for Clinical Laboratory Standards), M100-S12 Performance Standards for Antimicrobial Testing: Twelfth Information Supplement, 2002.

[17] NCCLS (National Committee for Clinical Laboratory Standards), M38-A Reference method for broth dilution antifungal susceptibility testing of filamentous fungi: Approved standard, 2002.

[18] S. Akanna, K. V. Prasad, E. K. Elumalai and N. Savithramma, Digest J. Nanomat. Biostruct. 5, 369 (2010). 